\title{
The Grammaticalization of "dao" in Mandarin Chinese
}

\author{
Hong Li \\ College of Humanity \\ Zhejiang University \\ Hangzhou, Zhejiang, People R China \\ hongli805030@126.com
}

\begin{abstract}
An examination to dao (arrive) in different syntactic environments helps to reinforce the multi-functionality of Chinese verb dao and the grammaticalization of it. Examples from Chinese suggest that 1) dao has changed to a preposition in Dao-NP-VP when V is lai (come) or $q u(\mathrm{go}) ; 2)$ dao is still a verb in V-Dao, the main function of which is directional complement or resultative complement; 3) dao has grammaticalized to a complement marker in $\mathrm{V}$-Dao-C if dao precedes a predicate structure. It is found that dao has developed from a notional word to a functional word, but it has not totally grammaticalized to be a typical functional word and is still on the process of further grammaticalization.
\end{abstract}

Keywords—dao; grammaticalization; multi-functionality; path

\section{INTRODUCTION: AIMS AND ORGANIZATION}

Grammaticalization is subject to the influence of the overall structural change of a language in a particular period of time. In this article, we explore this theoretical issue by analyzing the multi-functionality of Chinese verb dao and the grammaticalization of it. Dao is originally an independent verb which means arriving. Having been used in Chinese with high frequency, dao owns more multi-functional roles besides independent verb. In Eight Hundred Words of Modern Chinese Language, Lv Shuxiang ${ }^{[6] 151}$ defines that dao is both an independent verb and directional verb. Three usages can be found in the Contemporary Chinese Dictionary (the seventh edition): verb, adjective, and noun ${ }^{[13] 266}$. Dao may change over time into more functional roles such as a verb and preposition $^{[11] 1-10,}{ }^{[4] 144-145}, \quad$ an auxiliary ${ }^{[5] 50-56}$, and a complementary marker ${ }^{[16] 49-61}$.

The functional role of dao is controversial in the academic circle, so this paper investigates the multi-functionality of the Chinese verb dao from lexical source to various functional roles from a grammaticalization perspective. The following questions will be concerned:

(1) Is dao in Dao-NP-VP a preposition?

(2) Is dao in V-Dao a verb or a preposition?

(3) Is dao in V-Dao-C a complement marker?

This paper is organized into five sections. Section 2 gives some background to the concept of grammaticalization. Section 3 defines the functional roles of dao in three syntactic environments, offering the answers to three questions above, and introduces a new usage of dao, while Section 4 sums up the previous discussion, focusing on describing a grammaticalization path for dao. Section 5 provides a conclusion.

\section{GRAMMATICALIZATION: DEFINITIONS AND CONCEPTS}

The term 'grammaticalization' goes back to Meillet [7]131 and is traditionally understood as a process whereby a lexical item is reanalyzed as a grammatical morpheme or construction. This syntactic reanalysis is accompanied by a semantic reinterpretation of a very specific, lexical meaning into a more general, grammatical one. The relevant process is referred to as semantic bleaching, erosion, or reduction, or as desemanticization etc. ${ }^{[2] 579}$ Later, Givon places great emphasis on the dynamic process by suggesting 'today's morphology is yesterday's syntax.' ${ }^{[1] 43}$ Today, many scholars question the classic definition and hold that the study of grammaticalization should be widened. Therefore, they have redefined the term 'Grammaticalization refers to that part of the study of language that focuses on how grammatical forms and construction arise, how they are used and how they shape the language.' [9]1 All these definitions may have differences in expression, but they both confirm that grammaticalization belongs to the diachronic evolution process of language.

As for the motivations of grammaticalization, scholars hold different views in their works. The main relevant elements are semantic changes, pragmatics, psychology, language contact, cognition, and change of syntactic environment, etc.

\section{The GRAMMATICALIZATION OF CHINESE VERB DAO}

\section{A. Verb $\longrightarrow$ Verb-direction $_{(i)}{ }^{1} \longrightarrow$ Preposition}

In this part, we try to answer the first question: Is dao in Dao-NP-VP a preposition? Let's read the following two sentences:

(1) a. 我们强烈要求到学校去参观。

We strongly demand a visit to school.

(People's Daily, 2006-01-28)

b. 两位 “妈妈” 则坚持每天到学校看望孩子。

Two mothers insist on visiting their children at school every day.

(People’s Daily, 2006-01-28)

\footnotetext{
${ }^{1}$ Verb-direction $(i)$ refers to the former verb of conjunction predicate structure.
} 
Dao in (1a) is followed by the verb $q u$ (去), while dao in (1b) is followed by the verb kan wang (看望). We need to define whether dao in (1a) and (1b) is still a verb, or it has been changed to a preposition.

1) The functional role of dao in Dao-NP-VP

Shi Yuzhi ${ }^{[11] 1-10}$, Zhang Wangxi ${ }^{[15] 1-11}$ and Tong Guobin ${ }^{[14] 89-94}$ regards dao as a preposition in some syntactic environments. Here's an example listed by Shi Yuzhi.

(2) a. 他到北京了。

He has arrived in Beijing.

b. 他到北京去了。

He has gone to Beijing.

Shi Yuzhi regards that dao in (2a) is a verb and in (2b) a preposition. When dao appears simultaneously with the strong moving verbs like lai and $q u$, the displacement meaning of the whole sentence will be expressed by lai ( 来) and $q u$. Meanwhile, the directional characteristic of dao is enhanced, but the displacement meaning is reduced. So, dao has been grammaticalized to a preposition.

Zhu Dexi ${ }^{[17] 174}$ defines preposition as follows: 1. A pure preposition can only be used in conjunction predicate structure, and it can't be the only predicate in one sentence; 2. A preposition can't be repeated and be followed by le ( $了)$, zhe (着) and guo (过). Dao in (2b) comply with the definitions given by Zhu. We agree with Shi Yuzhi's view that dao in (2a) is a verb and in (2b) a preposition.

\section{2) Motivation of grammaticalization}

For most of the time, grammaticalization is first induced by the change of syntactic position of a full word. Functional words are mostly grammaticalized from verbs and adjectives. A verb in Chinese is usually put in the structure of SVO as a predicate. In this structure, only one verb acts as predicate, which is the core constituent of the sentence, so the action or state this verb expresses is real and notional. When the verb is no longer in the structure of SVO, it is not the only verb in the sentence, because another verb replaces its position to be the predicate of the sentence. This verb whose property of verb gets weak is no longer the main verb in the sentence (like dao in $2 b$ ), but used as a secondary verb in serial verb construction. When a verb frequently used as a secondary verb, its grammatical position will be gradually fixed, its meaning will become more and more abstract. If it keeps going, its grammatical function will change from the constituent of the predicate to the modifier or complement of the sentence. The further bleaching of word leads to the grammaticalization of verb, from lexical unit to grammatical unit. So, in the process of grammaticalization, the change of syntactic position and the influence of the structure is very important.

Here's an example provided by Tao Zhenwei ${ }^{[12] 155-157}$ :

(3) a. 到汉中讨张鲁

go to Hanzhong and launch an attack towards Zhang lu

b. 到学校去开会

go to school and have a meeting
Tao Zhenwei claims that dao in (3a) has been degraded to a secondary verb and in (3b) has been grammaticalized to a function word. Two verbs in serial verb construction express the time sequence of actions. The meaning of dao in (3a) has been bleaching, which can be understood as the preposition wang (往), because the phrase dao Hanzhong doesn't mean that they have arrived in Hanzhong, but Hanzhong is the destination of their action. When dao's grammatical position is fixed, the function of dao is reanalyzed and the serial verb construction is changed to adverbial head noun structure. The grammaticalization keeps going, dao in (3b) is no longer the constituent of the predicate, but the modifier of the sentence.

The conclusion can be drawn for defining the functional role of dao in Dao-NP-VP. When dao appears simultaneously with $l a i$ and $q u$ in one sentence, dao is placed before the verbal phrase, emphasizing the grammatical features of preposition. Dao has changed to be a preposition in (1a). When dao appears simultaneously with other verbs, it hasn't been fully bleaching, but still remains the meaning of motion, expressing the syntactic function of verbs like dao in (1b).

\section{B. Verb-direction $\left(\right.$ (ii) ${ }^{2} \longrightarrow$ irectional Complement $\longrightarrow$ Resultative Complement}

In this part, we try to answer the second question: Is dao in V-Dao a verb or a preposition? Let's read the following three sentences:

\section{(4) a. 游客爬到树上拍照}

Tourists climb up the tree to take photos. (People's Daily, 2013-06-03)

b. 写给总书记的信收到了。

The letter to secretary-general has been received.

c. 咱说到就做到。

(People's Daily, 2018-02-17)

We must keep our words.

(People's Daily, 2011-12-20)

Dao in the previous sentences appears after a verb, we need to define whether dao in (4a), (4b) and (4c) is still a verb, or it has been changed to a preposition.

\section{1) Controversial argument towards dao in V-Dao}

Scholars hold different views towards the functional roles of dao in V-Dao. Some claim that dao in V-Dao is a preposition ${ }^{[7] 57}$; here $\mathrm{V}$, the main verb of a sentence, can be replaced by most verbs, and $d a o$, a preposition, refers to the ending point of a certain action. Liu Ziyu ${ }^{[5] 52-53}$ argues that dao in V-Dao is a verb with two reasons: 1. By checking the meaning of dao in historical documents and mandarin Chinese, when V in V-Dao is a walking verb, dao is a verb expressing the real action. Dao means to reach a place, especially at the end of a journey. 2. The construction V-Dao-O can be changed to predicate-complement structure by adding de (得) or $b u$ (不). For example, when inserting de or $b u$ into the phrase pa dao shu shang (爬到树上), we are certain that both pa de dao shu shangand pa bu dao shu shang are acceptable and understandable. Expanding a construction by adding de or $b u$ is

\footnotetext{
${ }^{2}$ Verb-direction $(i i)$ refers to the latter verb of conjunction predicates structure.
} 
an important characteristic of predicate-complement structure. We agree with Liu Ziyu that dao in V-Dao is a verb.

Huang Borong and Liao Xudong ${ }^{[3] 71}$ in Modern Chinese point out that verb-direction expresses the direction of motion. Zhu Dexi ${ }^{[18] 128}$ defines that directional complement is a complement acted by verb-direction and is read in a light tone. Then, we come to a conclusion that dao in (4a) is regarded as verb-direction, in (4b) as directional complement and in (4c) as resultative complement.

\section{2) Motivation of grammaticalization}

The change of syntactic relations causes the change of semantic meaning, leading the notional words to grammaticalize, and finally play the functional role of a construction. So the change of semantic meaning is one of the important factors of grammaticalization. In the process of grammaticalization, a notional word grammaticalizes into a function word, generally because it usually appears in some syntactic position that is suitable to express some grammatical relation, then leading to the bleaching of semantic meaning and further realizing the fixation of syntactic position, finally turning to a function word.

Let's examine dao in the following two syntactic

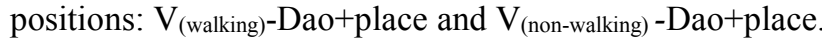

(5) a. ….., 需要跑到县城去领取包裹。 ..., need to pick up the package in town. (People's Daily, 2018-05-26)

b. …… 及时将父亲送到德州的一所大医院。

Father was sent to one of Dezhou's big hospital in time.

(People's Daily, 2018-06-06)

Dao in (5a) is a verb-direction and the verb pao (run) is a walking verb. The notional verb pao expresses the motion meaning, while dao points out the motion direction of the agent, but the displacement meaning is still remained. Dao in (5b) has been grammaticalized. Dao doesn't point out the motion direction for agent, but the ending point of the patient. Thus, dao has been grammaticalized from verb-direction to directional complement.

Metaphor is a cognitive approach of using one concrete concept to understand another abstract concept. The cognitive principles determine that the direction of metaphoric transfer is from the concrete to the abstract. When metaphorization enters into grammaticalization, it also motivates unidirectionality in change. Heine et al. (1991) argue that there is unidirectionality in metaphorical mappings as follows ${ }^{[10] 17-24}$ :

\section{Person $>$ Object $>$ Space $>$ Time $>$ Quality}

In following constructions, the meaning of dao gradually becomes more abstract from top to bottom, which can demonstrate the drive of metaphoric mapping in the grammaticalization.

(6) a. V-Dao + place 我回到了北京。 I went back to Beijing. (People’s Daily, 2006-01-28)

b. V-Dao + time
一年一场风, 从春刮到冬。

The wind blows the whole year, from spring to winter.

(People’s Daily, 2018-06-07)

c. V-Dao + quantity

有的地区地下机井甚至打到了七八百米深。

The underground well in some districts have been dug to $700-800$ meters.

(People's Daily, 2015-06-03)

Dao in (6a) is a directional complement, expressing the arriving meaning. Dao in (6b) and (6c) demonstrate the result of the action in time and quantity. Thus, dao has been grammaticalized from directional complement to resultative complement.

\section{Resultative Complement $\longrightarrow$ Complement Marker}

In this part, we try to answer the third question: Is dao in V-Dao-C a complement marker? Let's read the following two sentences:

\section{(7) a. 每次都吃到撑。}

$\mathrm{Sb}$. eats sth. to be totally stuffed.

(People's Daily, 2017-06-15)

b. ……, 被这种壮阔的场面 “感动到起鸡皮疙㾂”。

..., I was deeply moved by the magnificent scene.

(People's Daily, 2016-12-21)

$\mathrm{C}$ in (7a) is a word and $\mathrm{C}$ in $(7 \mathrm{~b})$ is a predicate structure. We need to define whether dao in (7a) and (7b) is a complement marker.

\section{1) Dao in V-Dao-C: a complement marker}

Liu Ziyu ${ }^{[5] 50-56}$ argues that the predicate structure after dao is an emphasis to the degree or state of the result. $\mathrm{C}$ is no longer the result of $\mathrm{V}$-Dao, and dao has a closer relationship with V. There's no such lexical meaning of dao left in this structure that dao has grammaticalized to a structural particle. Zhang Yisheng ${ }^{[17] 49-61}$ think that when $\mathrm{X}$ in A-dao-X changes from substantive object to predicate object or complex sentences, the transitivity of dao is gradually reduced. Dao is grammaticalized to a function word, a complement marker. Zhang put forwards two functional criterions for marker word dao: 1. dao is a complement marker, closely combined with its former verb; 2. dao can't be followed by le, otherwise, dao is not a marker, but a verb. Then, we come to a conclusion that dao in (7a) is regarded as resultative complement and in (7b) as complement marker.

\section{2) Motivation of grammaticalization}

Hopper and Traugott ${ }^{[9] 39}$ insist that the main mechanisms of grammaticalization are reanalysis and analogy. Reanalysis occurs in horizontal combination level of language and refers to the same surface structure. After the reanalysis, the internal structure of the language combination redraws boundaries for pragmatic or other reasons, which changed phoneme, lexical, combination way of syntax from the bottom. Reanalysis is considered to be the most important mechanism of grammaticalization, but it doesn't mean that it always causes grammaticalization. The grammaticalization is just one of the consequences of reanalysis. Reanalysis can derive new syntactic structures, for example, $\mathrm{C}$ in $\left[\mathrm{V}+\left[\begin{array}{ll}\text { dao } & \mathrm{C}\end{array}\right]\right.$ construction originally refers to the result of dao, when $\mathrm{C}$ 
expresses the degree or state of V-Dao, dao will be syntactically closer to $\mathrm{V}$, and finally the construction is reanalyzed to $[[\mathrm{V}$ dao $]+\mathrm{C}]$. Here's some instances.

(8) a. 我把自己逼到没有退路。

I let myself in such life without a turning back.

(People's Daily, 2017-04-14)

b. 爱树爱到骨子里

frantically love trees

(People’s Daily, 2017-03-03)

c. ......危险到一只鸟撞过来就会要了阿汤的命。

It is dangerous to such an extent that Tang will be killed if a bird hits him.

(People's Daily, 2015-07-24)

According to Zhang Yisheng's criterion discussed above, dao in $(8 \mathrm{a}, 8 \mathrm{~b})$ can be followed by le, which means that dao is a verb, remaining the motion function and tense aspect property. $\mathrm{C}$ in (8c) is a predicate structure. Dao in (8c) attaches to the preceding verb, which can't be followed by le, so its transitivity is reduced and has been totally grammaticalized to a complement marker.

\section{Resultative Complement $\longrightarrow$ Preposition}

1) A Buzzword: gei dao (给到)

This part introduces a new expression which is popularly used recently. Let's take a look at the following examples:

(9) a. 我这边给到平台的资金成本要达到 $30 \%$ 。

The cost of funding I gave to the platform reaches to $30 \%$.

(People's Daily, 2018-05-21)

b. $\cdots \cdots$, 能够给到别人一种健康的感觉。

It can give others a healthy feeling.

(People's Daily, 2018-05-21)

Gei has the arriving meaning of dao, so dao is the component of semantic redundancy, and then becomes a preposition.

\section{2) Motivation of grammaticalization}

Language contact is one of the motivations of grammaticalization, especially on new grammaticalization phenomenon. This contact includes connections between language and another language or dialects of a language itself. Language contact can enrich language expression. In order to enrich language expression, people will use language creatively to generate the grammaticalization. Dao in $(9 \mathrm{a}, 9 \mathrm{~b})$ expresses more vividly, which is often used in Cantonese, but now emerges in Mandarin. Dao in gei dao has been grammaticalized from resultative complement to preposition.

\section{THE MUlTi-FunCtionality OF DAO AND ITS GRAMMATICALIZATION PATH}

\section{A. The Multi-functionality of dao}

Through the changing process from the lexical verb in Pre-qin dynasty to the complement marker in Chinese structure V-Dao, dao has experienced a series of semantic change and grammaticalization process. Answers to three questions I proposed at the beginning of this article are: 1. Dao in Dao-NP-VP becomes a preposition; 2. Dao in V-Dao is a verb; 3. Dao in V-Dao-C is a resultative complement when $\mathrm{C}$ is a noun phrase; Dao in V-Dao-C is a complement marker when C is a predicate structure. There is not only one grammaticalization path for dao because dao hasn't been totally grammaticalized to preposition, but it has been gradually developed to a function word.

\section{B. The Grammaticalization Path of dao}

According to what have discussed, we reconstruct three grammaticalization path of dao in synchronic perspective as follows:

The first path: Verb $\longrightarrow$ Verb-direction ( the former verb of conjunction predicate structure $) \longrightarrow$ Preposition.

The second path: Verb $\longrightarrow$ Verb-direction (the latter verb of conjunction predicate structure $) \rightarrow$ Directional complement $\longrightarrow$ Resultative complement $\longrightarrow$ Complement marker

The third path: Verb $\longrightarrow$ Verb-direction (the latter verb of conjunction predicate structure $) \longrightarrow$ Directional complement $\longrightarrow$ Resultative complement $\longrightarrow$ Preposition

\section{CONCLUSION}

It is widely acknowledged in the general grammatical theory that the cline is one of the grammaticalization features. The development of language can be described by the process of grammaticalization, moving in the direction of "word $>$ function word / enclitic morpheme > suffix". The grammaticalization of dao is not the same direction, for example, dao as a complement marker is not grammaticalized from the function word. The preposition function and complement marker function of dao are formed because of the different developing direction of lexical verb. In the process of grammaticalization, the motivations are the change of syntactic environment, semantic change, metaphor mapping, and reanalysis.

\section{REFERENCES}

[1] Givon, Talmy, "Historical syntax and synchronic morphology: Anarchaeologist's fieldtrip," Chicago Linguistic Society, 1971 (7): 394-415.

[2] Heine, B., “Grammaticalization,” In: Joseph, B. D., Janda, R. D. (Eds). The handbook of Historical Linguistics. Blackwell, Malden, Mass, 2003, pp. 575-601.

[3] Huang Borong \& Liao Xudong, Mandarin Chinese Language (Volume II). Beijing: Higher Education Press, 2007. (In Chinese)

[4] Liu Danqing, Word Order Typology and Preposition Theory. Beijing: Commercial Press, 2003. (In Chinese)

[5] Liu Ziyu, "The Grammaticalization of the V-Dao-C Verb-Complement Construction in Cantonese and the Grammatical Explanation of Its Mutually Complementary Distribution to the V-De-C Verb-Complement Construction," Linguistics Study, 2006 (6): 50-56. (In Chinese)

[6] Lv Shuxiang, Eight Hundred Words of Modern Chinese Language. Beijing: Commercial Press, 1999. (In Chinese)

[7] Ma Beijia, Modern Chinese Preposition. Beijing: China Publishing House, 2002. (In Chinese)

[8] Meillet, A., L' evolution des formes grammaticales. Scientia (2), 1912.

[9] Paul J. Hopper, Elizabeth Closs Traugott, Grammaticalization (Second Edition). Cambridge: Cambridge University Press, 2005.

[10] Shen Jiaxuan, "A Survey of Studies on Grammaticalization," Foreign Language Teaching and Research (IV), 1994: 17-24. (In Chinese) 
[11] Shi Yuzhi, "The Influence of Time's Unidimensionality on Preposition Derivation," Studies of the Chinese Language, 1995 (1): 1-6. (In Chinese)

[12] Tao Zhenwei, "The Grammaticalization of dao," Journal of Hebei Polytechnic University: Social Science Edition, 2006 (5): 155-157. (In Chinese)

[13] The Dictionary Editorial Department of Chinese Academy of Social Science, The Contemporary Chinese Dictionary (the seventh edition). Beijing: Commercial Press, 2016. (In Chinese)
[14] Tong Guobin, “The Grammaticalization Process of dao,” Yindu Journal, 2006 (2): 89-94. (In Chinese)

[15] Zhang Wangxi, "A Semantic Mechanism of the Basic Prepositions Derivation in Chinese," Chinese Language Learning, 2004 (2): 1-11. (In Chinese)

[16] Zhang Yisheng, "The New Complement Marker dao in Contemporary Chinese," Contemporary Linguistics, 2014 (1): 49-61. (In Chinese)

[17] Zhu Dexi, Lectures on Grammar. Beijing: Commercial Press, 1982. (In Chinese) 